\title{
Thermodynamic analysis of a condensing evaporator in an evaporative gas turbine cycle
}

\author{
Aleksi Mankonen ${ }^{1, *}$, Juha Kaikko $^{1}$, Esa Vakkilainen $^{1}$, and Vitaliy Sergeev ${ }^{2}$ \\ ${ }^{1}$ Lappeenranta University of Technology, P.O. Box 20 FI-53851 Lappeenranta, Finland \\ ${ }^{2}$ Institute of Power and Transport Systems, Peter the Great Saint Petersburg Polytechnic University, \\ Saint Petersburg, Russia
}

\begin{abstract}
Low efficiency is the main stumbling block preventing the widespread adoption of small-scale gas turbines in distributed energy production. The evaporative gas turbine cycle has been proposed as a way to improve efficiency, but the large number of components required make the configuration complex and expensive. The condensing evaporator is a component that simplifies the evaporative gas turbine cycle. The heat and mass exchanger device is designed for an externally fired application, which means that the flue gas stream is replaced by moist air. The air-water mixture condenses inside a tube bank, releasing heat to the evaporating water film on the other side of the tubes. Similar inventions include the tubular humidifier and the Maisotsenko compressed air saturator, which also aim to make the evaporative gas turbine cycle more economically feasible. Available theory focuses on either humidification towers or evaporative condensers in HVAC applications. The tubular humidifier has been analyzed in a similar manner as humidification tower since the flow configurations of the two components are similar. However, the theory of humidification towers is not directly applicaple to the condensing evaporator. This study proposes a method of analysis of the condensing evaporator in power generation.
\end{abstract}

\section{Introduction}

Distributed generation of electricity allows rapid reaction to demand, provides better power quality under many circumstances and offers an alternative to investment in distribution capacity [1]. Using micro gas turbines is a promising way to implement a distributed electricity network [2]. External firing in gas turbines enables the use of solid biomass fuels that are an essential primary energy resource in a distributed energy system. However, the electrical efficiency of an externally fired microturbine (EFMT) is only $17 \%$ [3]. Such efficiency can be achieved by feeding the hot exhaust air to the combustor [4]. In contrast, the efficiency of a recuperated, commercial directly fired microturbine can exceed $30 \%$ [5].

Adding moisture to a gas turbine cycle working fluid has a positive impact on efficiency [6]. There are numerous ways to introduce the moisture. The most popular processes include

* Corresponding author: mankonen @ student.lut.fi 
steam injection and approaches based on the evaporative gas turbine cycle. The evaporative cycle differs from steam injection in that the water evaporates into the working fluid instead of boiling in a separate steam generator. The evaporative cycle has the potential to achieve efficiencies similar to or even higher than combined cycles and the evaporative cycle is the most efficient of the humidified gas turbine cycles [7]. The evaporative cycle is estimated to be economically suited to the microturbine application as well. An evaporative cycle with an EFMT has been demonstrated to yield an electrical efficiency of $30 \%$ [8]. Low temperature level heat can be used in the evaporative cycle, but the process requires a large amount of components. In an evaporative gas turbine cycle, there are usually two heat exchangers for preheating the injection water: a compressor aftercooler and an economizer in the turbine exhaust. There is also a massive humidification tower. The steam-injected cycle on the other hand, requires only a rather simple steam boiler. An example layout of an evaporative cycle is presented in figure Fig. 1 .

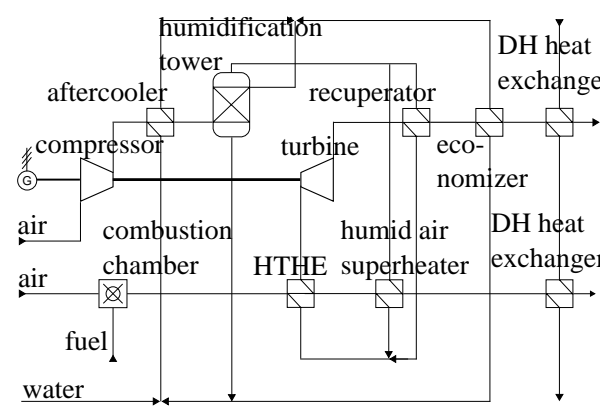

Fig. 1. Evaporative micro gas turbine cycle

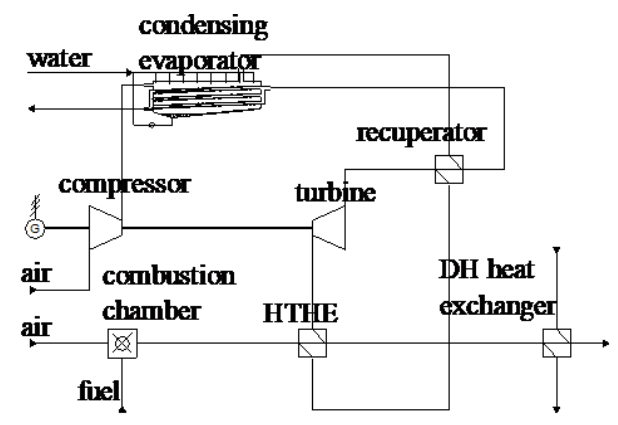

Fig. 2. Evaporative gas turbine cycle with a condensing evaporator

A number of new components have been proposed that aim to combine the tasks of traditional evaporative cycle components. Dalili [9] carried out experiments on a tubular humidifier. The prototype apparatus performs the tasks of the economizer and humidification tower in one component. However, the proposed configuration still includes an aftercooler. The Maisotsenko compressed air saturator [10] combines all of the components of an evaporative cycle into one tube-shell heat exchanger and evaporator. It cools the compressed air by means of evaporative cooling, simultaneously moisturizing part of the air. Hot flue gas is used to humidify the rest of the air and to superheat it.

Alander [11] has proposed a device similar to a tubular humidifier, which is used without an aftercooler. The moisturizing water stream is not warmed in a separate heat exchanger. The device uses the heat of the hot gas directly to evaporate water and achieve humidification. It is designed for an externally fired application. Therefore, humid air flows on both sides of the humidifier, which also allows condensation of the hot stream. A device with this configuration can be considered a condensing evaporator and this study focuses on performing thermodynamic analysis of such devices. The device is presented in Fig. 3. An evaporative cycle using a condensing evaporator is presented in Fig.2. A numerical model is developed in this study to determine the expected performance of a condensing evaporator. 


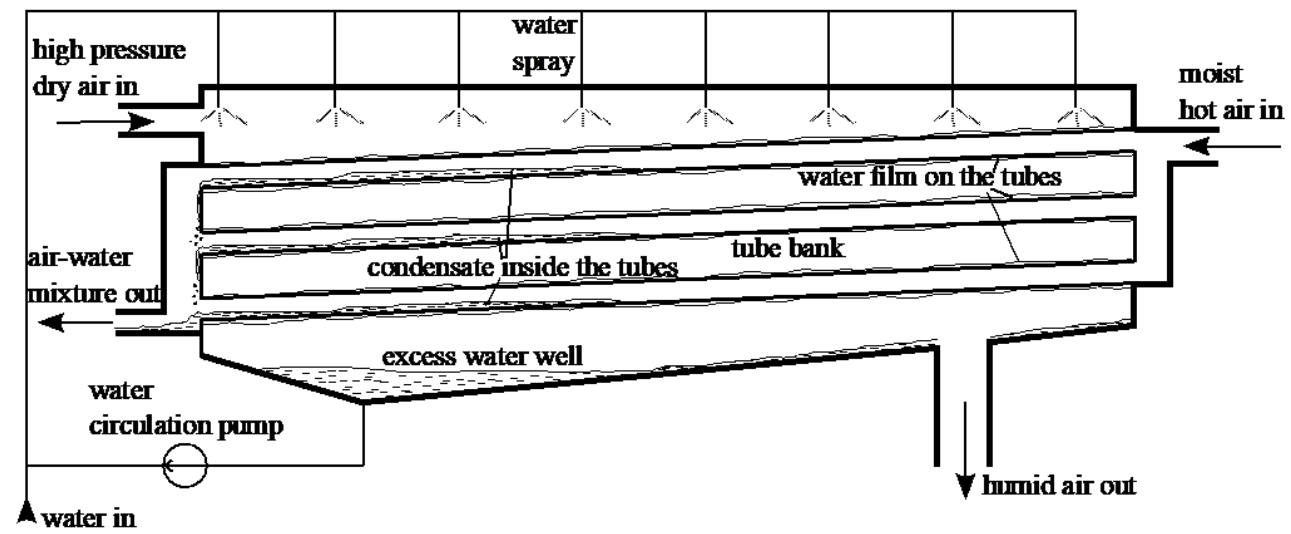

Fig. 3. Graphical presentation of condensing evaporator

\section{Model development}

Dalili [9] describes the saturation curve-operation line for a packed bed humidification tower. A modification of this approach has been used in this study to produce a humidification diagram for a condensing evaporator. The modifications have to be done, since there is an additional source of heat in a condensing evaporator i.e. the condensing hot stream inside the tubes. In a packed bed humidifier, the injection water has enough sensible heat to provide the heat for evaporation.

Accurate and fast calculation of the thermodynamic properties of humid air is crucial to this work. An open source software project, CoolProp, features a thermophysical library containing formulations for humid air properties according to Hermann et al. [12]. CoolProp includes the IAPWS-IF97 [13] formulation for water and steam as well. CoolProp is used in determination of saturated water-air mixture properties in this work. In the formulation of Hermann et al., the psychrometric calculations of moist air are based on the virial equation of state. The virial equation of state consists of the ideal part, and the deviation from the ideal behavior is accounted for by virial terms. The model considers virial terms up to second order. The basis of the model is the Hyland-Wexler model [14], but the authors have made improvements by using more accurate data for the ideal properties of air and a more sophisticated calculation method for the virial terms [12]. Ji et al. [15] conducted a survey of different humid air properties calculation methods and concluded that the ideal gas model differs considerably from the ideal mixing model and real gas model by Hyland-Wexler. Furthermore, they concluded that validation of the models at elevated temperatures is currently impossible due to a lack of experimental data.

The Mollier diagram of moist air (Mollier diagram or Mollier chart) is similar to the American psychrometric chart [16]. It presents the temperature and relative humidity curves in the enthalpy-humidity plane and it is constructed in such a manner that the perpendicular enthalpy-humidity co-ordinate plane is sheared so that the temperature lines become as horizontal as possible. However, the greater the temperature the greater the slope of the temperature curves becomes. Furthermore, at high humidity, the temperature lines become curved. The conventional Mollier diagram has such temperature and humidity range that the temperature lines are virtually horizontal. This representation is convenient in many HVAC applications.

When analyzing the condensing evaporator, some modifications have to be applied to the Mollier diagram. Firstly, the humidity and temperature ranges are significantly greater than in climate control applications. They have an order of magnitude up to $0.3 \mathrm{~kg}_{\mathrm{w}} / \mathrm{kg}_{\mathrm{da}}$ and 300 
${ }^{\circ} \mathrm{C}$, whereas the standard Mollier chart applies only up to $0.02 \mathrm{~kg}_{\mathrm{w}} / \mathrm{kg}_{\mathrm{da}}$ humidity and $40{ }^{\circ} \mathrm{C}$ temperature. For this reason, it was decided to use a perpendicular temperature-humidity coordinate plane, as used also in [10] for analysis of the Maisotsenko humidifying process. Bell et al. [17] have also used a similar approach in construction of the psychrometric chart.

The modified Mollier diagram is presented in Fig.4. Since the temperature-humidity grid is fixed, the enthalpy lines become curved. The diagram is drawn for pressure of $0.4 \mathrm{MPa}$, although the code produces values for up to $10 \mathrm{MPa}$ pressure. The vertical axis is also used to indicate partial water vapour pressure in the stream being humidified. The enthalpies denote enthalpy per kilogram of humid air.

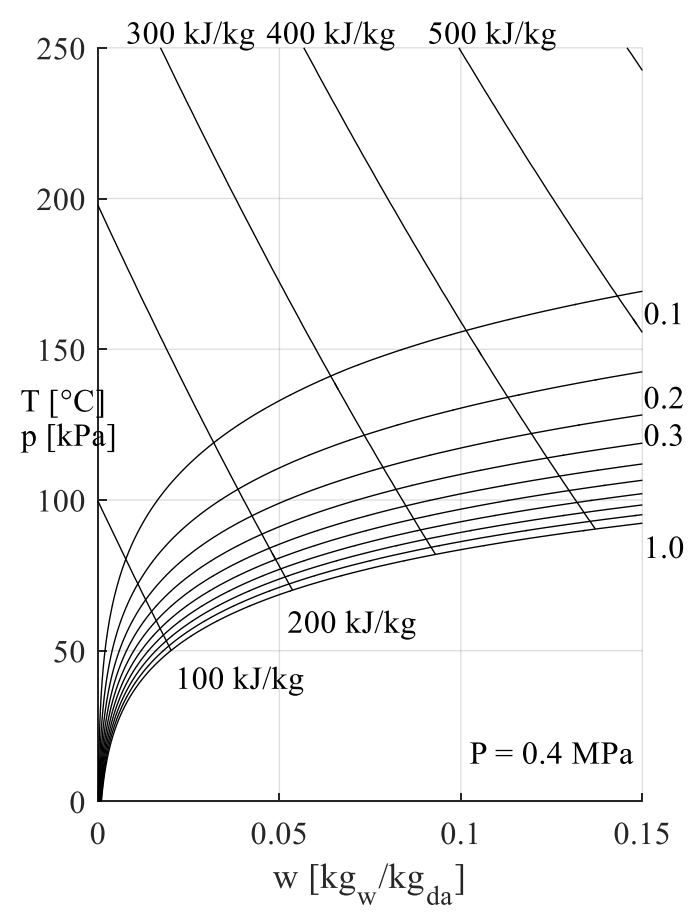

Fig. 4. Mollier diagram for humid air at 4 bar

The principle used in humidification tower design can be applied to a condensing evaporator. The evaporator is divided into small volumes and energy balances are solved for each volume. The division is presented in Fig.5. This method can also be referred to as a finite volume method as per [18]. The conservation equation 1 for mass and energy is solved by applying the divergence theorem and calculating fluxes at the surfaces. The purpose of the design tool is to determine the temperature and vapour pressure profiles.

$$
\frac{\partial \rho}{\partial t}+\nabla \cdot(\boldsymbol{v} \rho)=\nabla(\boldsymbol{\Gamma} \nabla \rho)+S
$$




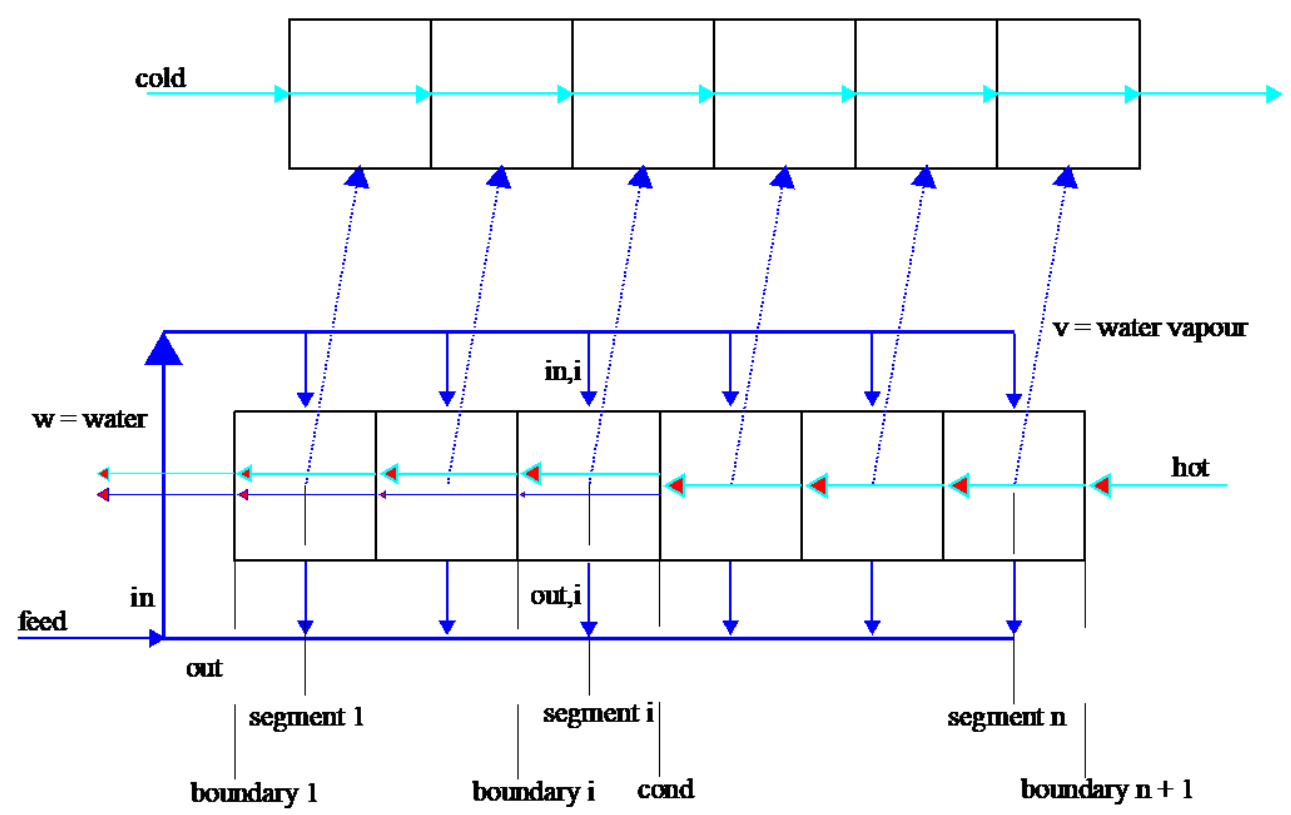

Fig. 5. Division of control volumes

The simulation is carried out by feeding the input values that are given by the gas turbine process. They include the mass flow rates, pressure levels and the hot side moisture content. Based on the input, the code solves the humidification diagram and draws it on the Mollier chart.

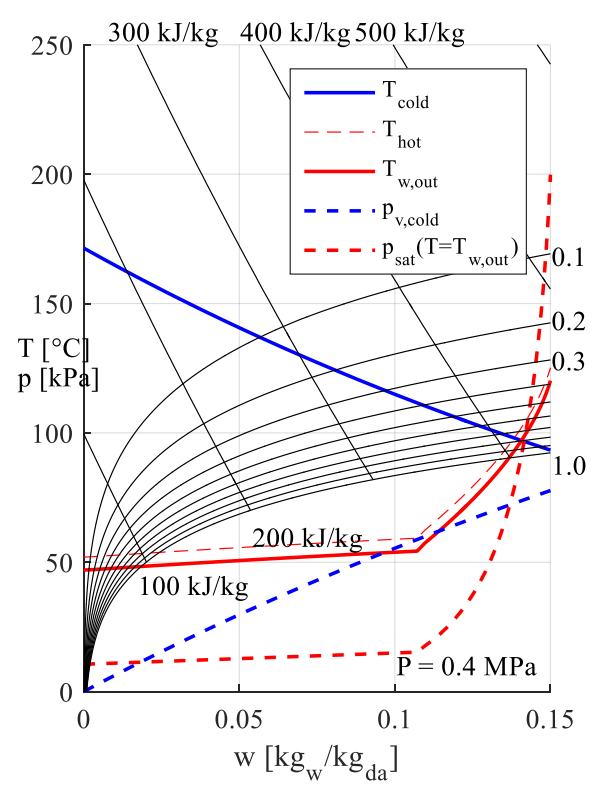

Fig. 6. $52{ }^{\circ} \mathrm{C}$ hot outlet, $0,15 \mathrm{~kg}_{\mathrm{w}} / \mathrm{kg}_{\mathrm{da}}$

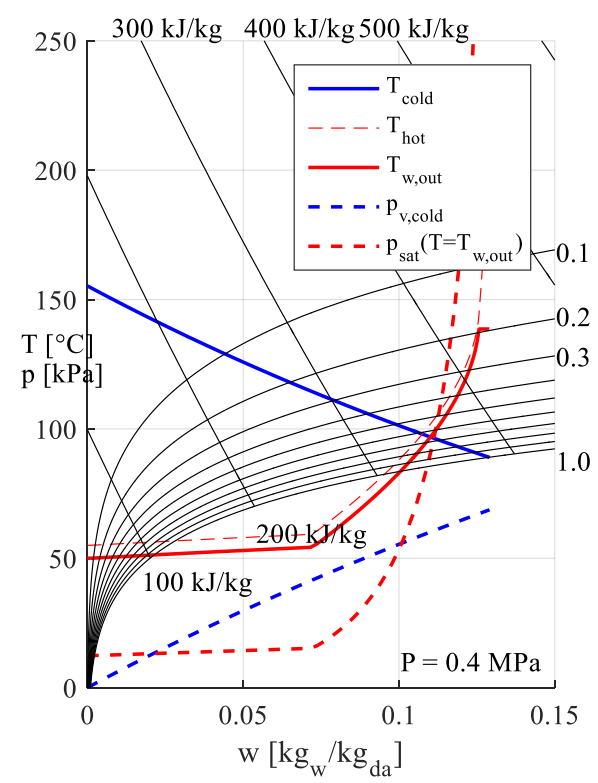

Fig. $7.55^{\circ} \mathrm{C}$ hot outlet, $0,15 \mathrm{~kg}_{\mathrm{w}} / \mathrm{kg}_{\mathrm{da}}$ 


\section{Results}

Aim of the model is to develop understanding on whether the condensation evaporation phenomenon occurs with a given set of parameters. Pressure levels were chosen $1 \mathrm{bar} / 4 \mathrm{bar}$ for the hot a and cold sides respectively. These pressure levels are typical for an externally fired micro gas turbine application.

In the first set of simulations, the same dry air mass flow rate is chosen for both fluids. The hot side outlet temperature is varied in order to determine how much heat can be extracted and transferred to the cold side. The results are presented in Fig.6 - Fig.9. It can be noted that only the last two simulations present cases, where the mass transfer can take place throughout the evaporator. Only in the last two diagrams, the saturation pressure of the water film (dashed red line) is constantly above the partial vapor pressure of the cold stream (dashed blue line). The first set of simulations indicate that the amount of condensation energy extracted is rather small in comparison with the sensible that is extracted from the hot side. The near-horizontal section of the hot side temperature indicate condensation and that section is small compared to the non-condensing section.

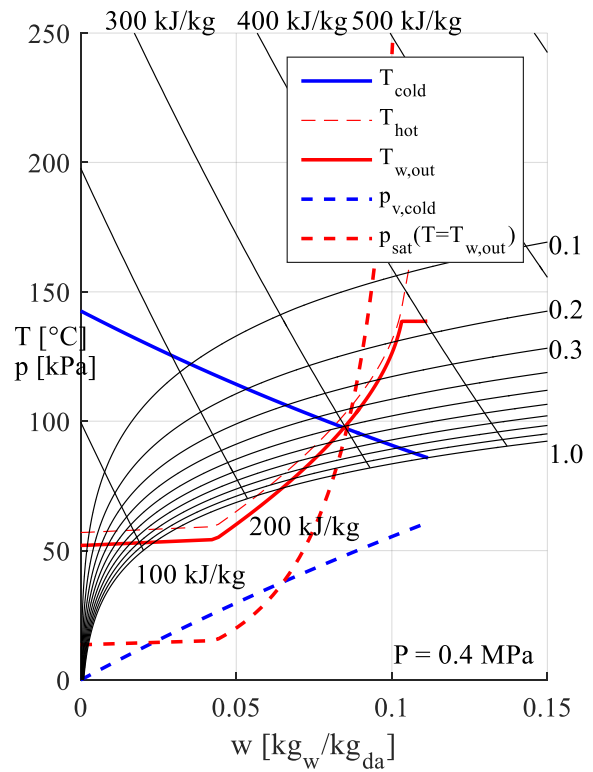

Fig. 8. $57^{\circ} \mathrm{C}$ hot outlet, $0,15 \mathrm{~kg}_{\mathrm{w}} / \mathrm{kg}_{\mathrm{da}}$

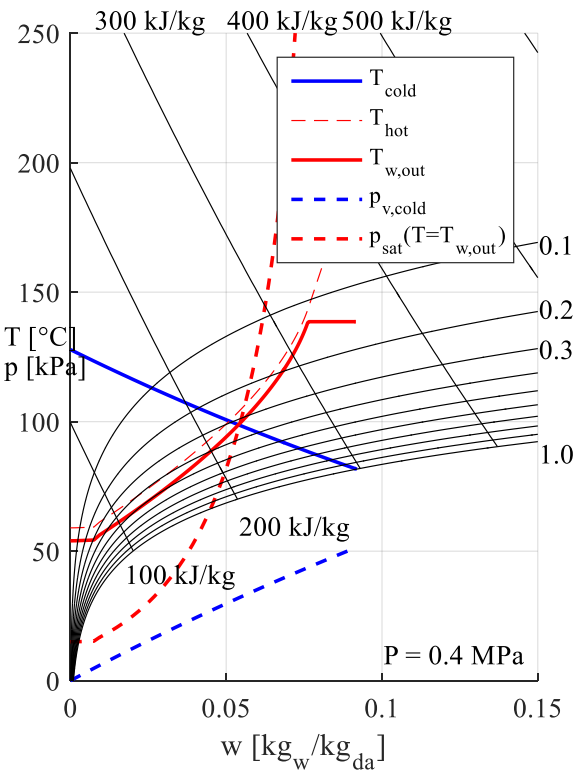

Fig. $9.59^{\circ} \mathrm{C}$ hot outlet, $0,15 \mathrm{~kg}_{\mathrm{w}} / \mathrm{kg}_{\mathrm{da}}$

In the second set of simulations, presented in Fig.10 - Fig.13, the effect of hot side moisture content is assessed. Dry air mass flow is kept constant. In these simulations, the hot outlet temperature has to be increased in order to maintain the needed vapour pressure difference. The higher moisture content increases the total mass flow of the hot stream and provides more heat. On the other hand, higher outlet temperature decreases the heat extraction. According to the results, the overall moisture content of the cold stream increases slightly due to the higher moisture content in the hot stream. 


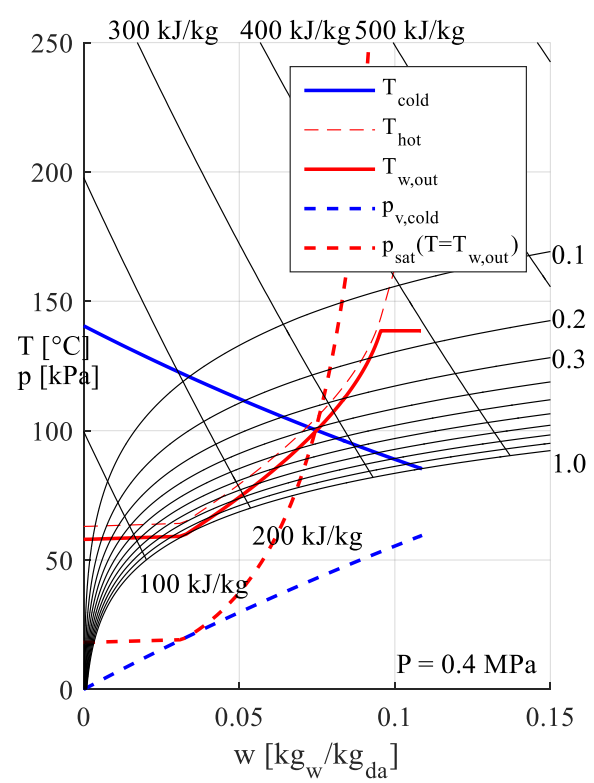

Fig. 10. $63{ }^{\circ} \mathrm{C}$ hot outlet, $0,20 \mathrm{~kg}_{\mathrm{w}} / \mathrm{kg}_{\mathrm{da}}$

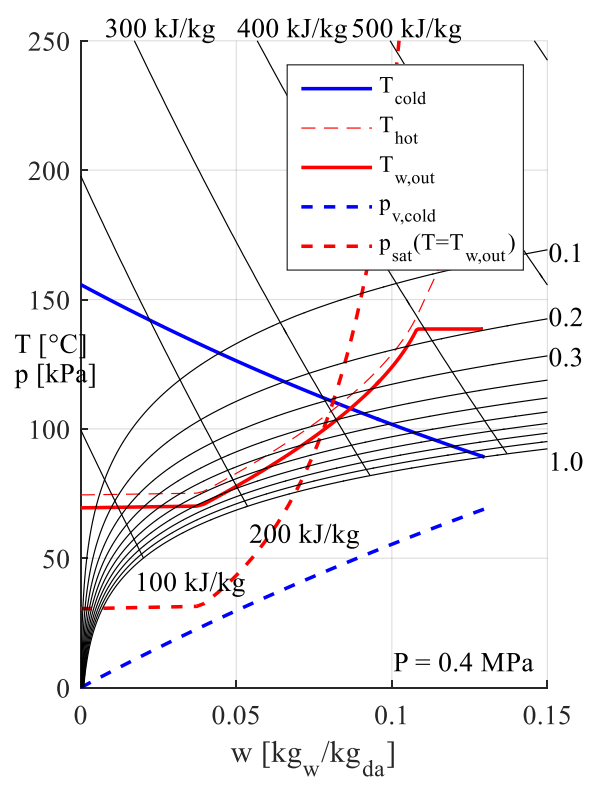

Fig. 12. $74,5^{\circ} \mathrm{C}$ hot outlet, $0,40 \mathrm{~kg}_{\mathrm{w}} / \mathrm{kg}_{\mathrm{da}}$

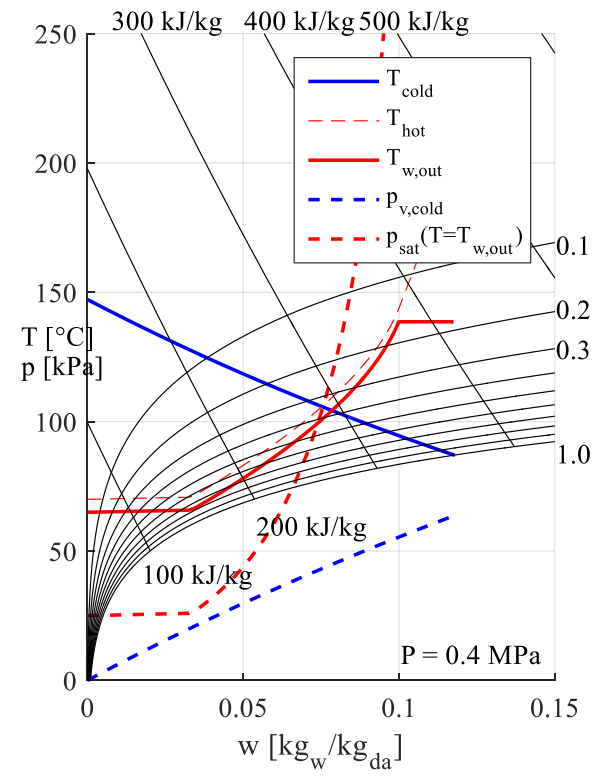

Fig. 11. $70{ }^{\circ} \mathrm{C}$ hot outlet, $0,30 \mathrm{~kg}_{\mathrm{w}} / \mathrm{kg}_{\mathrm{da}}$

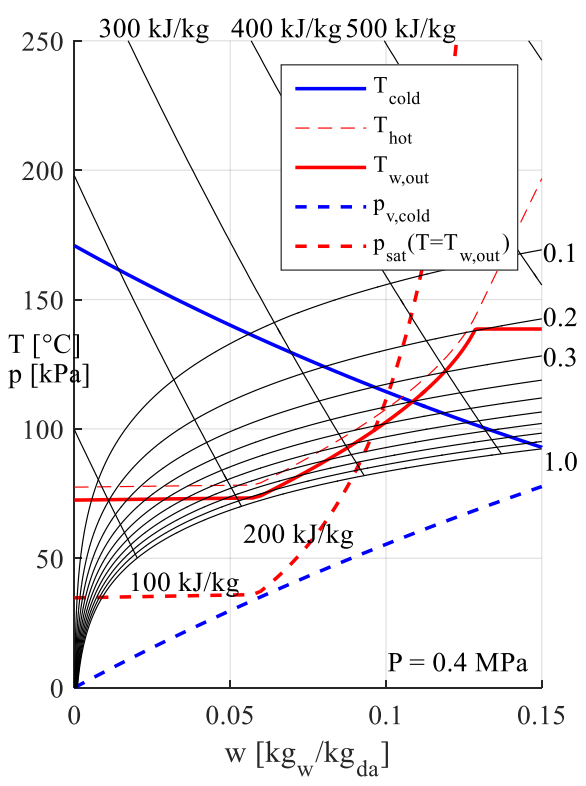

Fig. 13. $77,5^{\circ} \mathrm{C}$ hot outlet, $0,50 \mathrm{~kg}_{\mathrm{w}} / \mathrm{kg}_{\mathrm{da}}$ 


\section{Discussion}

According to the simulations, it is relatively difficult to find suitable parameters so that simultaneous condensing and evaporation would take place. The simulations suggest that when the cold fluid is very dry, the latent heat of condensation can be utilized. Once the cold fluid contains more water, the temperature level needed for further humidification becomes higher than the condensation temperature on the other side. In the cases, where simultaneous condensing and evaporation take place, the latent heat of condensation is small compared to the sensible heat released by the hot fluid.

The share of latent condensation energy can be increased by using more humid hot stream. The first set of simulations is used to model the case when the humidity remains constant in the further gas turbine process. The second set of simulations model the case when some additional water is introduced later on in the process. In the second case the humidity of the hot stream is increased from $0.15 \mathrm{~kg}_{\mathrm{w}} / \mathrm{kg}_{\mathrm{da}}$ to $0.5 \mathrm{~kg}_{\mathrm{w}} / \mathrm{kg}_{\mathrm{da}}$. This gives a greater share of condensation energy and slightly more humidity to the cold stream.

The results suggest that the condensing evaporator performs well at low humidity levels. Therefore, the component could useful in an application, where there is a great mass flow of very dry air that needs to be humidified to a moderate humidity. These simulations are subject to future research.

\section{Acknowledgement}

Jenny and Antti Wihuri Foundation awarded a grant for doctoral students to the first author. Authors want to express their gratitude for that grant since it supports the research of distributed energy production in their organization.

\section{References}

1. G. Pepermans, J. Driesen, D. Haeseldonckx, R. Belmans ja W. D'haeseleer, Energy Policy 33 (787) (2005)

2. C. M. Bartolini, F. Caresana, G. Comodi, L. Pelagalli, M. Renzi ja S. Vagni, Energy Conversion and Management 52 (781) (2011)

3. K. A. Al-attab ja Z. A. Zainal, Applied Energy (138) (474) (2015)

4. D. Pritchard, Biomass Fuelled Indirect Fired Micro Turbine, 2005.

5. G. Xiao, T. Yang, H. Liu, D. Ni, M. L. Ferrari, M. Li, Z. Luo, K. Cen ja M. Ni, Applied Energy (197) (83) 2017

6. W. D. Paepe, M. M. Carrerro, S. Bram, A. Parente ja F. Contino, Energy Procedia (105) (1712) 2017

7. M. Jonsson ja J. Yan, Energy (30) (1013) 2005

8. D. Marroyen, S. Bram ja J. De Ruyck, Asme. Turbo Expo: Power for Land, Sea, and Air, (2) 1999.

9. F. Dalili, Kemiteknik 2003

10. K. Wicker, Power (147) (29) 2003.

11. R. Alander, Arrangement in a gas turbine process, Patent, 2011

12. S. Herrmann, H.-J. Kretzschmar ja D. P. Gatley HVAC\&R Research (15) (961) 2009

13. W. Wagner ja A. Kruse, Properties of Water and Steam: The Industrial Standard IAPWS-IF97 for the Thermodynamic Properties and Supplementary Equations for Other Properties : Tables Based on These Equations, Springer-Verlag 1998 
14. R. W. Hyland ja A. Wexler ASHRAE Transactions (89) (520) 1983

15. X. Ji, X. Lu ja J. Yan, Applied Thermal Engineering (23) (2213) 2003

16. D. P. Gatley ASHRAE JOURNAL (46) (16) 2004

17. I. H. Bell, E. W. Lemmon ja A. H. Harvey, International Journal of Refrigeration 2017

18. F. Moukalled, L. Mangani ja M. Darwish, The Finite Volume Method in Computational Fluid Dynamics: An Advanced Introduction with OpenFOAM and Matlab, 1st toim., Springer Publishing Company, Incorporated, 2015 